\title{
It Takes a Village: Perspectives from a Multidisciplinary Team Addressing the Needs of HIV+ Refugees in Canada
}

\author{
Heather Mah and Nicole Ives
}

\begin{abstract}
This study explored the perspectives of a multidisciplinary team at an HIV clinic in Canada mandated with addressing the diverse needs experienced by their HIV+ refugee clients. Specifically, the study sought to identify barriers and facilitators to effective service provision for refugee persons living with HIV/AIDS (PHAs) in the context of a multidisciplinary team. Data were acquired using qualitative methods. Individual interviews were conducted with a sample of seven service providers who work directly with $H I V+$ refugees on a multidisciplinary team at an HIV clinic in Canada. Respondents identified a need for improved community services for HIV+ refugees, specifically legal aid and service from immigration doctors and pharmacies. Cultural and linguistic issues also shaped respondents' work with refugees; suggestions for addressing these issues included HIV-related and culturally competent training. Implications for policy, practice, and research are included.
\end{abstract}

\section{Résumé}

Cette étude a exploré les points de vue d'une équipe multidisciplinaire dans une clinique du VIH au Canada ayant pour mandat de répondre aux divers besoins de leurs clients séropositifs. Plus précisément, l'étude a cherché à identifier les obstacles et les possibilités à l'égard de la prestation de services efficaces pour les personnes réfugiées vivant avec le VIH/sida (PVVIH) dans le cadre d'une équipe multidisciplinaire. Les données ont été recueillies en utilisant des méthodes qualitatives. Des entretiens individuels ont été menés auprès d'un échantillon de sept intervenants travaillant directement avec des réfugiés séropositifs au sein d'une équipe multidisciplinaire dans une clinique du VIH au Canada. Les répondants ont identifié un besoin d'amélioration des services communautaires pour réfugiés séropositifs, en particulier de l'aide juridique et des services de médecins et de pharmacies à l'immigration. Les questions culturelles et linguistiques agissent aussi sur le travail des répondants avec les réfugiés; une formation culturellement compétente liée au VIH figure parmi les suggestions pour traiter de ces questions. Les incidences pour la politique, la pratique et la recherche sont aussi discutées.

\section{Introduction}

Refugee ${ }^{1}$ persons living with HIV/AIDS (PHAs) in Canada are a vulnerable population who experience multiple challenges. These challenges include navigating immigration and settlement processes, ${ }^{2}$ in addition to dealing with an HIV diagnosis. In 2007, there were an estimated 33.2 million people worldwide with HIV; approximately 58,000 live in Canada. ${ }^{3}$ Persons who were born in an HIV-endemic country are overrepresented in Canada's current HIV epidemic. ${ }^{4}$ In 2007, approximately 13 per cent of newly reported HIV cases were refugees who arrived in Canada and tested positive for HIV, the largest proportion of people being born in Africa and the Middle East (59 per cent), followed by the Americas, Asia, and Europe, respectively. ${ }^{5}$ Of the 1,050 HIV+ applicants for Canadian permanent residency in 2006 and 2007, 994 were refugees, refugee claimants, or family class members. ${ }^{6}$

The majority of recent research conducted in the area of refugees living with HIV in Canada has been primarily quantitative, based on statistical prevalence, sociodemographics, or HIV policy. ${ }^{7}$ There is limited research on the 
experiences of professionals whose services are bound by policies, who interact daily with HIV+ refugees, and who observe first-hand refugees' resettlement challenges in Canada. ${ }^{8}$ Multidisciplinary teams have existed within the health care field as a means to address the multiple needs of diverse communities and populations for decades in the realm of HIV care. " "Multidisciplinary" characterizes a team where each individual discipline brings its profession to the group while maintaining its own identity within interactions with other disciplines. ${ }^{10}$ In many settings, this approach has been focused on utilizing multiple service providers from different disciplines in order to provide integrated services to persons with HIV, primarily in the context of co-occurring physical and mental health issues and substance abuse. ${ }^{11}$ Multidisciplinarity has also been described as a situation where each member of the team provides distinct knowledge and expertise as a means to optimize the "efficiency of decision making and meeting clients" needs in a more holistic fashion." 12 Studies have found that multidisciplinary approaches can improve compliance with HIV primary care visits, which is associated with increased retention in care and improved treatment adherence. ${ }^{13}$

There is limited research available regarding the perspectives of a multidisciplinary team mandated to address the myriad needs of persons living with HIV, and, more specifically, how a multidisciplinary team could contribute to effectively addressing the diverse needs and experiences of HIV+ refugees. ${ }^{14}$ One recent study described its approach to primary health care service provision for refugees in general as "multidisciplinary," but did not describe the mechanisms of the multidisciplinary team beyond listing the disciplines connected with the clinic. ${ }^{15} \mathrm{~A}$ multidisciplinary team approach can be beneficial to HIV+ refugees by utilizing a holistic framework that addresses not only medical needs, but psychological, psychosocial, spiritual, legal, and nutritional challenges as well. For this study, the term "multidisciplinary" was adopted to reflect that the study site (an HIV clinic) existed within a hospital setting with distinct roles and disciplines. The purpose of the study was to explore the perspectives of a multidisciplinary team at an HIV clinic in Canada tasked with addressing the diverse needs experienced by their HIV+ refugee clients. Specifically, the study sought to identify barriers and facilitators to effective service provision for refugee PHAs within the context of a multidisciplinary team, addressing this gap in the literature.

\section{Immigration and Health Contexts of HIV+ Refugees in Canada}

Immigration and HIV are both areas that are strongly influenced by policies that are continually changing, requiring health professionals and other service providers to keep up to date in order to provide clients with the best possible service. In November 2001, the Immigration Act of 1976 was replaced by the Immigration and Refugee Protection Act (IRPA). In January 2002, Citizenship and Immigration Canada (CIC) added routine HIV testing to the Immigration Medical Exam (IME) for all immigrants and persons seeking refugee status arriving in Canada aged fifteen years and over. One section of IRPA, Article 38, does not specifically mention HIV as a criterion for exclusion but could consider PHAs "medically inadmissible." This could prevent immigrants from being granted permanent residency if it were deemed that their health condition would place excessive burden on public health services. ${ }^{16}$ Officially, however, refugees are exempt from Article 38, as they are "eligible by law to remain in Canada independent of their health status." 17 This highlights, in theory, the humanitarian nature of refugee admissions.

Currently, HIV is considered a "notifiable" disease rather than a "reportable" disease like tuberculosis or syphilis. This means that there are no mandatory conditions for follow-up for refugees who test HIV positive when arriving in Canada. Testing can ensure new cases of HIV entering Canada are treated and monitored, helping to reduce new infections. Little attention is paid, however, to the stigma that still exists surrounding HIV status. The IME's implementation of mandatory testing has caused an increase in the detection of HIV cases among immigrants and refugees coming to Canada, resulting in the essential need to research services available to this population.

Addressing only HIV diagnoses for refugee populations in Canada is not enough to meet all of their multiple needs. Addressing the physical health needs of refugees with HIV is of course critical, but their cultural, psychological, and resettlement needs should be addressed as well. Krentz and Gill emphasized the need for specific services for immigrants who possess distinct demographic and clinical characteristics requiring focused and different resources. ${ }^{18}$ Refugees are not a monolithic group as they possess different experiences and expectations of health and health care. ${ }^{19}$ Refugees may have experienced previous trauma in their home country and/or trauma from the migration journey, and are now facing a complex immigration system, experiencing challenges with adapting to a new culture and lifestyle, securing housing and employment, and facing systemic discrimination in addition to accessing medical treatment. ${ }^{20}$ These challenges combined make it difficult for refugees to negotiate the extremely complex immigration, welfare, and health care systems.

A qualitative study conducted in Toronto's African and Caribbean communities on their experience with 
stigma, denial, fear, and discrimination associated with HIV/AIDS found the "need to raise awareness about HIV, combat stigma and tackle systemic issues such as racism and unemployment which impact on the overall health of their communities."21 Ruppenthal explored HIV+ refugees' adjustment in Montreal and described their realities as experiences of trauma, complicated immigration negotiations, challenges accessing care, discrimination, family separation, isolation, cultural adaptation, uncertainty, and poverty. ${ }^{22}$ Additionally, Simich, Beiser, Stewart, and Mwakarimba identified financial insecurity, intergenerational strains, and gender role changes as further sources of stress for newcomers to Canada. ${ }^{23}$ Combining these factors with the realities of an HIV diagnosis that could include stigma, shock, denial, lack of information, new care regime, mental health issues, depression, and fear can be overwhelming. ${ }^{24}$ One study of mental health services for refugee PHAs in Toronto found that critical service needs included improved coordination and quality of services with HIVawareness training to reduce AIDS-related stigma and fear, language services, and increased mental health services. ${ }^{25}$ Respondents in a study of policy changes on refugee health in Toronto identified "an urgent need for interpretation services, case management and culturally appropriate food bank services." 26 Health outcomes are thus shaped by legal interventions as well as "social support, pre-migration experiences, citizenship and social status, access to education, employment, adequate housing and health services, personal coping resources, community connections and social inclusion." 27 Further, discrimination and social inequities experienced by PHAs of colour contribute to an increase of HIV risks by poor management of the disease, higher rates of depression, and other psychiatric problems. ${ }^{28}$ As a suggestion for an integrated HIV-prevention approach, Veinot emphasized that the concept of HIV/AIDS treatment should be implemented as a "continuum" to also include complementary therapies that address mental, spiritual, and emotional needs. ${ }^{29}$

\section{Multidisciplinary Teams Working with Refugee PHAs}

To address living with HIV/AIDS, it is critical to be able to treat the individual's needs on all levels: psychological, emotional, social, and spiritual, in addition to physical. This involves focusing more on the person than on the virus, ${ }^{30}$ which can often occur in a hospital and medical setting with health professionals. The study chose an ecological perspective to study multidisciplinary teams serving refugee PHAs. ${ }^{31}$ An ecological perspective explores the interconnectedness among the different layers of an individual's environment and how these influence one's development.
When employing an ecological perspective, it is critical to "understand how varying models of collaboration play out in differing ecological contexts" 32 in order to address the myriad needs of refugee PHAs. The nature of an HIV diagnosis and the subsequent "interacting biological, psychological, and social needs [of the person with HIV] should be addressed simultaneously rather than as separate, isolated dimensions" and thus necessitates the use of a multidisciplinary approach to care. ${ }^{33}$ One profession or area of expertise alone cannot address all the needs an HIV infection demands. In addition to combining knowledge from diverse disciplines, multidisciplinarity also means "ultimately expanding one's own repertoire and gaining an appreciation of other disciplines' perspectives." 34

A multidisciplinary approach requires many considerations, including within-team communication, community collaboration, role definition, and protection of client confidentiality. Most importantly, a client-centred approach should guide the multidisciplinary process. ${ }^{35}$ Key components to multidisciplinary collaboration include understanding multiple perspectives involved, willingness to share one's expertise, flexibility, acknowledging work of support staff, involvement of financial, managerial and administrative staff, implementation of staff support systems such as counselling, and knowing one's role within the team, as well as understanding the roles of team members. ${ }^{36}$ Professionals on an HIV multidisciplinary team are required to combine knowledge from their own discipline with an expertise on HIV/AIDS as well as be in regular, direct communication to prevent fragmentation and duplication of services. It is also important to share experiences to gain meaning from their work in a compassionate, trusting environment which can help to address the effects of job-related stress. ${ }^{37}$ This is essential when such stress includes work with refugee populations who have had traumatic life experiences and, in addition, the inevitable loss of patients from AIDS.

There are specific processes that are essential for multidisciplinary teams to function effectively including their organization (training, resources, and preparation), knowledge, communication, and interaction. ${ }^{38}$ Previous studies have described how there are challenges with defining roles within the team, distribution of power, division of labour, and establishing a standardized approach to care including executing services, evaluation, and monitoring systems. ${ }^{39}$ There are no known guidelines or standards for multidisciplinary care for PHAs in North America. ${ }^{40}$ The difficulty with establishing such guidelines also exists in the variance of HIV experience among individuals, especially those with complex needs. In a review of integrated HIV care for cooccurring substance abuse disorders and mental disorders, Soto et al. found that of the integrated HIV programs, "few 
described the mechanisms they developed to facilitate and support this type of collaboration." 41 There is no consensus within the literature on the collaborative structures and processes that are most effective. Working in collaboration amongst professions also challenges the long tradition of specialization, and subsequent fragmentation, of services in the health care field. ${ }^{42} \mathrm{HIV}$ treatment originated within a medical model, however, a holistic model is more inclusive of the social, psychosocial, and psychological needs of patients.

\section{Methods}

The method of inquiry into the experiences of a multidisciplinary team's work with refugee PHAs was a qualitative case study, specifically a within-site study of a single program. ${ }^{43}$ This approach was selected as the most relevant to depict the complexities of one unique case. The specific case studied was an HIV clinic multidisciplinary team. Through intensive analysis of a single case, researchers studied "a bounded system (a case) [...] through detailed, in-depth data collection [...] and [reported] a case description and casebased themes." ${ }^{4}$ As the unit of analysis, the multidisciplinary team was explored within its real-life context through interviews with individual team members. ${ }^{45}$ Qualitative methods were chosen to allow participants to give voice to their perceptions of the team's functioning, providing insight into the complex processes of working with refugee PHAs. ${ }^{46}$ As little is known about multidisciplinary teams' work with refugee PHAs, qualitative methods were appropriate for the study's exploratory nature, allowing for creation of categories to emerge from the data. ${ }^{47}$

This case of the clinic's multidisciplinary team is unique in that the clinic specializes in both HIV and refugee populations; other multidisciplinary teams in Canada focus either only on HIV (e.g., John Ruedy Immunodeficiency Clinic in Vancouver) or only on refugee health more broadly (e.g., Access Alliance Multicultural Community Health Centre in Toronto). By analyzing a unique case, the study sought to (a) document the functioning of a distinctive team-they represent front-line health and social service delivery for refugee PHAs; and (b) explore team members' perspectives on work with refugee PHAs, not only to determine the nature of a multidisciplinary team but also how additional members not always found on multidisciplinary teams add to the expertise of the group. ${ }^{48}$

\section{HIV Clinic Background}

The multidisciplinary team at the HIV clinic is comprised of thirty-three team members representing medicine (nurses and medical doctors), social work, psychiatry, psychology, pharmacy, nutrition, law, theology (chaplain), and administration. Additionally, the clinic has a clinical research team and operates an AIDS consultation phone line. Several of the professions were represented by one position, and some of these positions were part-time. The team provided care and treatment in English, French, and Spanish to HIV+ adults, a significant proportion of whom were HIV-infected refugees. In 2009, the clinic served between 1,300 and 1,400 patients, coming from eighty-five different countries. Over 20 per cent of the clinic's patients, approximately 300 to 400 , were refugees. Most of the clinic's refugee population originated from Africa, Latin America, and the Caribbean. Refugees were referred to the HIV clinic by immigration doctors after they arrived in Canada and had undergone the Immigration Medical Examination. Immigration doctors are designated by CIC to conduct the IMEs.

\section{Sample}

To recruit participants, a letter was sent to each team member and the study was presented at a psychosocial round meeting to all team members. The total sample consisted of seven HIV-clinic multidisciplinary team members, three women and four men. Due to team members' availability, only six of the nine disciplines were covered, although the six (Participant 1, social work; Participant 2, law; Participant 3, medicine-nursing; Participant 4, pharmacy; Participant 5, medicine-physician; Participant 6, medicine-physician; and Participant 7, psychology) were the members with the most active involvement with patients. The sample contained a combined total of seventy-nine years experience of working with PHAs. While all members were invited to participate, researchers targeted members to ensure the distribution of key variables in terms of discipline represented, length of team involvement, and level of participation on the team.

\section{Data Sources}

The primary data source was an in-depth individual interview of members of a multidisciplinary team that works with refugee PHAs. Open-ended, semi-structured interviews lasting 60 to 120 minutes were audiorecorded and transcribed verbatim. The interview guide asked the same questions to all participants, regardless of profession. The guide was composed of explanatory, interpretative, and evaluative questions that focused on multidisciplinary team role, perceptions of refugee clients' needs and how the team addresses them, dynamics of working on a multidisciplinary team, improvements that can be made to the team, and how they could be implemented. Some of the questions were adapted from an interview schedule developed by Sargeant and Jones used in their research on barriers young women with HIV experience when accessing primary health care in 
Vancouver. ${ }^{49}$ This guide provided consistency to the questions while allowing respondents the flexibility to digress on their own experiences. The secondary data source was a document review of information provided by the clinic including annual reports, studies conducted at the clinic, and statistics of client demographics. Researchers took notes on these materials, highlighting themes which had emerged from the interviews for triangulation.

\section{Data Analysis}

Data were analyzed using a "holistic analysis," employing a thematic analysis across the entire case to present descriptions, themes, and interpretations that were connected to the whole case. ${ }^{50}$ In order to identify similar themes, codes and themes that emerged from team members' interviews were compared to each other. Transcribed interviews were read for codes created to reflect the research questions as well as areas which emerged from the data and reread and recoded for more specific codes and subcodes. NVivo, a qualitative software program, was used to assist with data analysis. Member checking was conducted by sharing data and interpretations with participants. Individual interview transcriptions and generated themes were provided to each participant for verification, feedback and further input.

\section{Study Findings}

Perspectives provided by members from the multidisciplinary team illustrate how a multidisciplinary approach supports refugee PHAs in meeting their multiple complex and urgent needs. Team members identified various challenges and strengths associated with working on a multidisciplinary team, working with HIV+ refugee patients, and collaborating with professionals in the community connected to refugee PHA populations.

\section{Challenges}

Bringing different disciplines together to produce the best outcome for clients is a challenge with any client population. Not everyone will agree with the practice approaches and opinions that each member contributes due to varying backgrounds and expertise. However, this collaboration is critical when working with client groups such as refugee PHAs who have complex medical, psychosocial, spiritual, legal, and nutritional needs. Participants described challenges pertaining to working on a multidisciplinary team with HIV+ refugees, specifically: (a) addressing differences between team members, (b) linguistic and cultural issues, (c) need for HIV-related and culturally competent training, and (d) need for improved community services.

\section{Addressing differences among team members}

Differences in values, perspectives, and approaches to practice can naturally arise within a team, especially when there are numerous professions and backgrounds involved. How these differences are addressed is an important aspect of maintaining effective multidisciplinary team functioning and development. Different expertise and standpoints each team member contributes can create varied and conflicting views on how best to meet patients' needs. Moreover, while individual styles and personalities can offer diversity to a team, they can also cause disagreements. Several participants highlighted the challenges that arose from negotiating different styles among team members but noted that, in the end, as described by one participant, differences are worked out,

extremely diplomatically because one of the advantages of why we work well here is we're a small town. You cannot be anything but respectful and patient because [otherwise] it's going to backfire. You cannot live in a small community and work in conflict.

Some participants remarked on differences regarding how much effort team members are expected and willing to offer to refugee patients. As Participant 2 commented, "In terms of the multidisciplinary thing ... there's a broad difference in how willing people are to go the extra mile." For example, Participant 1 expressed frustration with another team member who was felt to be uncooperative with assisting with paperwork to help increase a patient's monthly support, noting:

Now it doesn't matter how much you're saving their life for HIV, this person is starving. This person doesn't have a life. This is horrific what is going on with this person, this is not a way to live. But if you just fill this [form] out I will get $\$ 300$ more for this person. $\$ 300$ when you're poor will make you want to come to your medical appointment. You'll digest your medication better, you'll be less lonely, maybe less depressed. There's just constantly [asking], "Please fill out this form."

On the other hand, this team member acknowledged the additional work team members are willing to do that receives no extra recognition or compensation: "People on the team go the extra mile, they write these letters, etc ... but they're not compensated for it. It's not recognized as an expertise, it's not recognized as a field that requires extra on-going training." Strategies members used to facilitate healthy team functioning included addressing differences directly by using diplomacy, flexibility, and willingness to compromise with each other. 


\section{Linguistic and cultural issues}

Refugees arriving in Canada who cannot speak English or French can experience language barriers, which affect their access to and understanding of health care and social services. Team members stated how the availability of translation services at the HIV clinic improved patients' support and interaction. However, even with support, members still described patients who were illiterate in English and/or French as well as cultural differences and misunderstandings created by language barriers, which could be problematic when communicating information regarding HIV treatment, prevention, and policy.

One's cultural beliefs can shape perceptions of HIV, including the denial of an HIV diagnosis, approaches to treatment, and misinformation about HIV transmission and "cures." Team members described how some of their African patients still have strong beliefs in "black magic" as a form of HIV treatment, while others accept sexual relationships with multiple partners and are against the use of condoms for protection from HIV. Team members discussed how some patients arrived at the clinic believing that an HIV diagnosis was a death sentence; had they remained in their home country where treatment is not readily available, that belief could hold some truth.

Participant 4 communicated with some patients in Spanish or with a translator and stated how these patients were sometimes reluctant to learn English or French after arriving in Canada. Without acquiring a new language, this can be problematic for patients in their everyday life, particularly obtaining employment and accessing services when interpreters are not available. With the highest proportion of refugees at the clinic from Haiti (12 per cent), team members expressed challenges with communication in Creole. Following the earthquake in Haiti in January 2010, Canada may receive an increase in Haitians coming as refugees or through the family reunification program. Participant 6 stated:

If we see more [refugees] coming for instance from Haiti which has about $2 \%$ of the population infected [with HIV] ... we could expect a few more patients coming in, but they're going to be coming in probably only speaking Creole, or maybe Creole and French and they're going to be unaware of how our system works ... coming from a very impoverished background. It's a big job.

Despite language barriers, team members described having the ability to convey the necessary information to patients and an appreciation for patients' experiences with having to communicate in a language that is not their native tongue. Participant 2 encountered a woman who had "become an expert at hiding her illiteracy" in French and English despite living in the United States for 20 years. Participant 7 described an example of providing information to patients and the less-than-ideal communication strategies sometimes employed to work across language barriers:

The most remarkable case I had was a woman who spoke not a word of English or French and we couldn't find a translator who spoke her language, so we have to work a lot through her husband and through her third language which was Arabic ... we needed to tell her, your husband's seropositive, we need to test you and you need to protect yourself and use condoms for sexual intercourse ... taboo topics to talk about with a Muslim woman [who] never used condoms before...

Some participants discussed gaining cultural understanding by learning from personal experiences that inform interactions with patients. Participant 4 explained how spending time travelling in Africa helped to understand the strong cultural importance of the role of motherhood for patients and stated:

A women has to have children, that's her role in the community and often when they get here and learn that they are HIV+, they're afraid that they won't be able to have kids anymore and often this affects them more than the fact of knowing that they're HIV+. I see that a lot so what I do is the first time I see them I always tell them, do you know it's possible still to have kids? And often I see their eyes light up because I feel I touched something that's important for them.

Participants described cultural differences with some of their patients from Africa who are not used to the custom of appointments and approach the concept of time differently. Culturally, the concept and role of medication can vary and refugee $\mathrm{PHAs}$ need to adapt to taking pills at the same time every day, experiencing various side effects, making appointments, and refilling prescriptions. Addressing communication challenges with patients enhances their understanding of their situation and available services and treatments. Building on personal experience and working with patients can strengthen workers' recognition of cultural diversity between patients and provision of culturally relevant support.

\section{Need for HIV-related and culturally competent training}

Despite the existence of HIV for almost three decades, there are still some misinformed and uninformed professionals working in the HIV community. Participants emphasized the need for further training for both team members and health professionals with whom they collaborate. 
Participants identified the following topics requiring further training: HIV policy, approaches to informing patients of positive HIV test results, client confidentiality, and HIV prejudices. In a field where policies are continually changing and new research and treatments are being updated and introduced, ongoing training and workshops for team members are essential. Team members were concerned as to how to logistically provide training for new members and replace members when they leave, particularly those who have been with the team for numerous years and have developed relationships with the patients, knowledge about community resources, and relevant policies. Participant 5 discussed how within-team mentoring is used for training:

There's no formal training programs for anybody in HIV. There are a lot of training programs like mentoring programs for doctors out there, mentorship programs and stuff but there's not really a formal "I'm going to become an AIDS-ologist."

Participant 2 described how government officials who make decisions on refugee claimant applications and lawyers who are supporting refugees also require HIV training, especially if personal values conflict with their work. Participant 1 discussed how some members of the team also needed training to be more empathetic towards patients:

It would just be nice if somehow along the way [team members] could get that training so they could come to really, truly get to understand what that other side is about and in doing so see the whole person. I think that until they understand, if somebody's in front of them who hasn't eaten since 7:00 this morning and maybe they're nauseous and they took medication ... until there is a capacity to empathize, they'll never see the whole person.

Participant 2 further assessed that the current form of training at the clinic is insufficient, as "people have had to learn on their own or on their own as a group in the clinic and get up to speed, and that's regrettable. That's regrettable that it had to be done that way." Participant 5 discussed formal training required for professions working outside the HIV environment, and the overload of information there can be from all the various health concerns that currently exist. This participant also questioned whether there should be a formal qualification or certification process for HIV care:

There's really no proper way to teach medical people, doctors, to be qualified in dealing with HIV and the reason is there's no qualification exams, there's no certification process, there's no formal course work that they have to do.
Training can also provide consistency and a strategy to monitor workers' performances and patients' outcomes, though a team member questioned how feasible such a practice would be in addition the current heavy workload.

\section{Need for improved community services}

A common theme several team members referenced was a concern for the quality of service patients disclosed they received, in particular the quality of legal representation. Team members recounted patients who have paid to have a Personal Information Form (PIF) completed by lawyers, a document required to establish that a refugee's claim is credible. A PIF is supposed to encompass an individual's last ten years, including family members, previous jobs, and addresses. One member recalled seeing ones which were only a few lines long, incomprehensible, and inaccurate. Participant 2 criticized the quality and integrity of poor legal services given by lawyers:

The legal services people are getting is of such poor quality, it's absolutely discouraging, it makes you extremely cynical ... You know, if law was practiced properly, many, many more people would win [their cases].

This team member emphasized the importance of deadlines and how without proper legal support, missing deadlines can cause serious implications for refugees:

Law is a dangerous business in the sense that you cannot miss deadlines ... In the case of the woman who came to me recently, she told me her lawyer had gone into revision and I said to her repeatedly, "As soon as you hear from the decision the revision is negative you come running to me and we put stuff together in a package and send you off to your lawyer." As it turned out he never contacted her and she came to see me when she had a letter for deportation.

Participant 3 described refugees experiencing discrimination from pharmacists in the community, based on their immigration status, and being refused service so the pharmacists could avoid the reimbursement process, as it is lengthy and "bothersome" for them:

Some pharmacists told me that it could take months for [the Federal Interim Health Program] to get reimbursed and on a management or accountability side it can be bothersome for some pharmacists ... I've even seen pharmacists that refuse to serve a patient who was a refugee because of that and that's discrimination. 
Another service challenge team members expressed was concerning immigration doctors, the first point of service contact for many refugees arriving in Canada. One participant described the poor quality and lack of post-test counselling, resulting in patients being uninformed about their referral. As a consequence, patients arrive at the HIV clinic without understanding the nature of the referral received from the immigration doctor. Additionally, there can be a time gap from when patients have received their diagnosis and referral to when they actually reach the clinic. Timing is critical for refugee patients to receive support to address their immigration and HIV health and related needs. One participant stated how refugees can be overwhelmed with information when they first arrive and may not fully appreciate the HIV testing they undergo.

\section{Strengths}

Regardless of challenges encountered, team members described particular strengths they experienced through a multidisciplinary team working with refugee PHAs. These strengths included a commitment to a multidisciplinary approach that shares knowledge and expertise-critical for work with refugee PHAs-and collaboration with the broader community that is connected to refugee PHAs.

\section{Commitment to multidisciplinarity}

Across respondents, there was a theme of commitment to a multidisciplinary approach to care for refugees with HIV. They expressed a common focus on the necessity of all the different professions working together to meet patients' needs. Team members described feeling supported by other members, especially through effective communication, at the weekly psychosocial round meeting, by giving and receiving referrals, advice and feedback from colleagues, respecting each other's roles, knowing what to expect, and learning from each other. The basic elements of using each team member's knowledge and expertise to collaborate for the benefit of patients was evident. As Participant 1 described:

[Multidisciplinary] means [the] possibility of actually meeting the many needs of our clients. It means not being in isolation, it's knowing that whatever you can't do, another specialist takes over. It's a little bit the notion of the village that takes care of something.

Furthermore, Participant 2 stated how the different expertises combine as a team: "And the multidisciplinarity is true, I mean none of us feels that we alone can do anything. People have all their different experiences and expertise; no one person can do anything."
Participants spoke positively about the team's knowledge and expertise with patients, not only in the field of HIV but particularly with refugees. This knowledge and expertise has been developed by the longevity of workers at the clinic and their experience with refugee PHAs. Such a distinct clientele demands that workers maintain continuous, up-to-date knowledge on pertinent information related to research, policy, services, treatment, medication, and immigration throughout changing disease trends and legislation. Participant 1 described how refugee PHAs are their most vulnerable patients and how the team's knowledge has developed through experience: "We have other very vulnerable clients but [refugees with HIV] are considered by far to be the most vulnerable clients, so many come here from the time that we developed this expertise."

Participant 7 described how a multidisciplinary approach can benefit patients, noting, "The more I think you have different disciplines treated as an integral part of the team, the better the patient can benefit and the greater the voice the patient has. In HIV it's just the ideal field to bring all those together." Similarly, Participant 5 stated how collaboration increased efficiency by helping to reduce the workload, because "the work is done better because everybody's good in doing its own thing so we leave what's to the other to be done and we do what we can do best."

Within a team environment, roles can overlap, as members are required to go beyond their position to meet patients' needs. Essentially, team members may need to become knowledgeable in other backgrounds in addition to their own, such as a physician being informed about available community services or a social worker about new medications.

\section{Community collaboration}

A fundamental aspect of a multidisciplinary team approach is collaboration. When working with HIV+ refugee patients, collaboration also needs to be conducted with the greater community to ensure all of the patients' needs are met. Another strength respondents highlighted was the team's ability to utilize all of its resources and referring patients to other members, as well as community resources, when necessary. Participant 7 commented how the trusting relationships among team members enabled patients to consent to working with team members who represented professions with which patients had little familiarity or trust:

I've worked a lot cross culturally and worked a lot on multidisciplinary teams. The fact that people from some of the cultural backgrounds we're working with, even agree to go to a [particular professional] at all is an amazing thing, so it has a lot to do with 
the team and the team approach, the fact that I'm ... working next to a trusted team member.

Participants described how the clinic developed broad community contacts over the years, which assisted with resolving problems efficiently. They partner with pharmacists, immigration lawyers and law firms, immigration doctors, immigrant welcome centres, organizations for immigrants and asylum seekers, women's centres, hospices, HIV social housing, psychologists, obstetricians/gynecologists, food banks, HIV/AIDS organizations, private clinics, hospitals, and community health centres. Other participants discussed various connections with relevant institutions, such as the United Nations High Commissioner for Refugees (UNHCR), that have been developed with the clinic, contributing to a "cross pollination" across the community.

\section{Discussion}

Employing a Multidisciplinary Approach to Care for

$H I V+$ Refugees

Providing HIV care to refugees can be demanding. A multidisciplinary practice is an approach that considers their multiple needs as a collective team, to provide service as a continuum and reduce fragmentation. ${ }^{42} \mathrm{~A}$ multidisciplinary team enables patients to access essential resources efficiently but also facilitates their health professionals' case collaboration, contributing to continuity of service.

All participants spoke positively of a multidisciplinary team approach and how the collaboration of different disciplines, expertise, and knowledge benefits patients. These findings are congruent with the definition of "multidisciplinary" in the literature. ${ }^{51}$ However, team members found that defining and differentiating between the various roles on the team could become more problematic due to overlapping of roles demanded by patients' needs. Although the literature ${ }^{52}$ stated that overlap of roles can create barriers between team members, in some instances this overlap should not be viewed as a barrier, but rather as enhancing team functioning. Crossing boundaries between professions lends to the negotiation and evolution of roles, ${ }^{53}$ evidenced by participants' description of a desired new member-a health educator, a position that combines the expertise of a physician, nurse, social worker, and pharmacist.

Questions arose regarding differences in effort team members are expected and willing to provide for patients. How can team members establish boundaries and differentiate between what they are mandated to do and the support refugee PHAs actually require? How can team members maintain a high standard of service while managing high caseloads? What monitoring and evaluation systems can be implemented to ensure that refugees are receiving the best service possible? These concerns are connected to a high caseload that participants expressed managing daily. While there are numerous professions represented on the multidisciplinary team, several of these positions are filled by only one individual, some of whom work only part time. Team members' suggestions of additional positions on the team not currently represented (such as a community liaison to collaborate with community organizations, immigration doctors and lawyers, a health educator to improve HIV education and identify early vulnerabilities providing more prevention services, and an occupational therapist to address patients' physical and mobility needs) would contribute to more comprehensive coverage of patients' needs and a better distribution of the mandate to meet those needs through the team.

\section{Improving Refugee Services and Reducing Barriers}

Multidisciplinary team members highlighted the challenges that both they and their refugee clients encounter with community collaboration, specifically with legal aid, immigration doctors, and pharmacies. Efforts are needed to improve standards and reduce barriers to service accessibility and delivery.

Canada's immigration system can be extremely complicated and difficult to navigate, especially understanding legal language which can make forms and processes inaccessible to refugees. There are significant costs that can result from missing deadlines, including risks of deportation. A concern expressed by participants was the quality of legal service patients disclosed receiving. This reflects the findings by Li on the scarcity of immigration lawyers who are experienced in HIV and able to provide culturally relevant services. ${ }^{54}$

A health service challenge raised by participants was with immigration doctors who they felt were not obtaining informed consent properly, or not providing pre- and posttest HIV counselling. When undertaking HIV testing, doctors are required to obtain informed consent and to provide pre- and post-test counselling to patients. There have been discrepancies in the literature as to whether this occurs consistently in practice. ${ }^{55}$ Several participants confirmed that HIV counselling is not always being conducted with refugees. With immigration doctors being one of the first points of service contact for refugees, this is a valuable opportunity to provide them with information and support instead of contributing to a fall through the cracks of the system. A comprehensive health settlement program and surveillance system in addition to service monitoring and evaluation can better ensure follow-up is timely. ${ }^{56}$ The findings also revealed that refugees are being refused services, in particular from pharmacies, based on their health coverage. This 
reflects findings in the literature as well as popular media where physicians refused service to refugees because they are not familiar with the Interim Federal Health Program (IFHP), the paperwork is too laborious, and the reimbursement process is slow and lengthy. ${ }^{57}$ Researchers have advocated for the federal government to revise the IFHP to make the reimbursement process "transparent, smooth and accessible." 58 Revision to the program can reduce discrimination by service providers and make them more willing and able to assist refugees regardless of their health coverage.

Providing a practice that is informed by a theoretical framework that centres a refugee's ecological context and is integrated with an "understanding of the cultural norms, values, and beliefs of their home countries" 59 is essential for refugee PHAs who experience discrimination due to being a refugee, having HIV, or their sexual orientation. Participants expressed concern for patients who experienced discrimination from service providers, in particular, being refused service from pharmacies on the basis of being a refugee. This is similar to findings by Lawson et al. where focus group participants reported doctors who displayed "judgmental attitudes" towards patients requesting HIV testing. ${ }^{60}$ Cobos and Jones's study of providing health care to undocumented immigrant PHAs in the United States underscores the need to address discriminatory practices and call for health care providers to offer care regardless of immigration status. ${ }^{61}$

\section{Implications for Practice, Policy, and Research}

There are considerable benefits to utilizing a multidisciplinary approach with vulnerable populations such as refugee PHAs, including providing more congruity and less fragmentation in service delivery, the ability to address multiple clients' needs by combining expertise, and collaboration as a team. There is also a great need for improved HIV education services for service providers and the broader community connected to this population.

Service improvement could be achieved by providing targeted training opportunities for health and social service professionals working in the HIV community, from government officials to immigration doctors and new staff at the HIV clinic. Training could involve areas that should theoretically already be service standards but are not being implemented or monitored in practice. Formal, ongoing HIV training is essential to ensure current knowledge about the disease. Ongoing training is also essential to address homophobic and discriminatory attitudes and practice. It is important to highlight that while a multidisciplinary approach may improve access to services and resources for refugee PHAs, it does not guarantee that the content of those services is necessarily culturally relevant for them. ${ }^{62}$ Not only must interventions be culturally relevant for service users but the members who provide those services must be culturally competent as well. Team members must take into account a service user's cultural context, that is, his or her attitudes, beliefs, traditions, religion, perspectives on health, and so forth. They must also consider their own cultural contexts and explore how their contexts intersect with those of their clients. At the same time, one must remember that cultural context is not static, and that culture is "relative to time and social context." 63 Providing ongoing training underscores the idea that seeking cultural competency is a continual process-each new client has his or her own unique context which can become the space for cultural dialogue.

Cultural competency training can also help workers confront their own fears, opinions, and value judgments that arise when working with refugee PHAs. As participants identified, the HIV virus, its treatment, and affected populations are continually changing. Therefore, services also require the initiative and flexibility to adapt to these changes, such as an influx of refugee PHAs from Haiti presenting at the HIV clinic. Such service accommodation will continue to be challenging amidst budget, funding, staff, and resource constraints. However, there are demands for programs to offer employment assistance, specifically aiding refugees to have their previous education, credentials, and skills recognized in Canada. Collaboration is also needed internationally with refugee treatment and care for those who have been deported, to transfer patients' health information. Additionally, what are the opportunities for multidisciplinary teams to progress towards an interdisciplinary approach, where disciplines work together to create new innovations, perhaps in program and policy development and delivery?

Team members highlighted the need to improve the ways in which refugee claimant PHAs received health care coverage through the IFHP. Enrolling in and renewing coverage in the IFHP requires considerable systems literacy; participants stressed the challenges their clients have in maintaining coverage and navigating IFHP systems. From a policy perspective, the IFHP needs to become more accessible and understandable for patients in order to prevent expiry of health insurance and running out of HIV medication. An increase in social assistance entitlement, housing benefits, accessibility to transportation reimbursement, and scope and duration of legal aid services will greatly improve standards of living to refugees who may arrive in this country with minimal resources. Citizenship and Immigration Canada needs to improve its efforts to tackle the backlog of existing refugee claims so refugee claimants do not have 
to live in immigration limbo for years. Ending the limbo would bring certainty to their legal status and future life in Canada, enabling them to begin the process of family reunification and permanent resettlement.

Further research is warranted. Experiences of refugee PHAs who receive services at an HIV clinic would provide valuable insight from the service users' perspectives. Focus groups with refugee PHAs at an HIV clinic with a multidisciplinary team can explore multidisciplinary service provision from the clients' points of view and the extent to which they feel supported holistically. In particular, indepth research on vulnerable refugee PHA populations such as elders, women, queer, disabled, youth and children, and "non-status" can further inform current policies and practice. An examination of cultural competency with organizations working with refugees can further identify cultural needs. Experiences of refugee PHAs living in rural communities and their accessibility to services should also be explored.

\section{Study Limitations and Strengths}

The small size of the multidisciplinary team overall coupled with the demanding schedules of team members resulted in a relatively small sample size. However, the study's purpose was to explore experiences of professionals who are on the front lines of service delivery for HIV+ refugees through their narratives. A qualitative case study approach facilitated this. The study sought to illuminate the complexities of working on a multidisciplinary team "based on a more intimate knowledge of a smaller 'slice' of reality." 64 The goal was not to generalize, but to explore the experiences of the multidisciplinary team members who work with refugee PHAs and provide insights into service delivery for local, national, or international programs working with refugee PHAs. For example, providing integrated services, found to be effective in HIV care provision, ${ }^{65}$ can reduce fragmentation, but study findings support placing that approach in a holistic context that acknowledges the multiple ecological spheres shaping refugees' resettlement experiences. Study findings underscore the need to have those services provided by disciplines that represent those spheres, that is, by a multidisciplinary team.

\section{Notes}

1. The most widely accepted definition for "refugee" is based on the 1951 United Nations Convention relating to the Status of Refugees (United Nations General Assembly, 1951) as a person who owing to a well-founded fear of being persecuted for reasons of race, religion, nationality, membership in a particular social group, or political opinion, is outside the country of his nationality, and is unable to or, owing to such fear, is unwilling to avail himself of the protection of that country. For this study, "refugee" was used to refer to refugees, asylum seekers (in Canada, refugee claimants), and "non status" individuals in refugee-like situations, but the authors acknowledge the differences among these definitions. When distinct differences between the terms exist, for example when concerned with policy and eligibility, terms are used separately.

2. Nicole Ives, "More Than a "Good Back": Looking for Integration in Refugee Resettlement," Refuge 24, no. 2 (2007): 54-63.

3. United Nations Programme on HIV/AIDS and World Health Organization, "AIDS Epidemic Update: December 2007" (UNAIDS/07.27E/JC1322E), (Geneva: United Nations Programme on HIV/AIDS and World Health Organization, 2007); Alix Adrien, Vivian Leaune, Robert Remis, Jean-Francois Boivin, Erling Rud, Raymond Duperval, and G. E. Noel, "Migration and HIV: An Epidemiological Study of Montrealers of Haitian Origin," International Journal of STD \& AIDS 10 (1999): 237-42.

4. British Columbia Centre for Disease Control, "Trends in HIV Positive Immigrants and Reporting by Citizenship and Immigration Canada (CIC) 2000-2007" (2007), accessed June 26, 2009, http://www.llbc.leg.bc.ca/public/ PubDocs/bcdocs/432118/Report.pdf; Public Health Agency of Canada, "Canada's Report on HIV/AIDS 2005" (2005), accessed June 27, 2009, http://www.phac-aspc .gc.ca/aidssida/publication/survreport/index-eng.php; Public Health Agency of Canada, "HIV/AIDS in Canada among Persons from Countries Where HIV Is Endemic," HIV/AIDS Epi Updates, November 2007, accessed July 1, 2009, http://www.phac-aspc.gc.ca/aids-sida/publication/ epi/pdf/epi2007_e.pdf.

5. Public Health Agency of Canada, "HIV/AIDS Epi Updates, November 2007."

6. Laura Bisaillon, "Human Rights Consequences of Mandatory HIV Screening Policy of Newcomers to Canada," Health and Human Rights 12, no. 2 (2010), accessed February 23, 2011, http://www.hhrjournal.org/index.php/hhr/ article/viewArticle/373/580.

7. British Columbia Centre for Disease Control, "Trends in HIV Positive Immigrants"; Canadian HIV/AIDS and Legal Network, "Canada's Immigration Policy as It Affects People Living with HIV/AIDS,"2 007, accessed July 20, 2009, http://mqhrg.mcgill.ca/i/bisaillon/Immigration_policy _and_PHA_2007.pdf; ; Alana Klein, "HIV/AIDS and Immigration: Final Report," 2001, accessed June 25, 2009 , http://pubs.cpha.ca/PDF/P7/19034e.pdf; Hartmut Krentz and Michael John Gill, "The Five-Year Impact of an Evolving Global Epidemic, Changing Migration Patterns, and Policy Changes in a Regional Canadian HIV Population," Health Policy 90 (2009): 296-302; Marie-Jo Ouimet, Marie Munoz, Lavanya Narasiah, Vanessa Rambure, and José Correa, "Pathologies courantes chez les demandeurs 
d'asile à Montréal: prévalence et facteurs de risque associés," Canadian Journal of Public Health (November-December 2008): 499-503; Public Health Agency of Canada, "HIV/ AIDS Epi Updates, November 2007"; Kevin Pottie, Praseedha Janakiram, Patricia Topp, and Anne McCarthy, "Prevalence of Selected Preventable and Treatable Diseases among Government-Assisted Refugees," Canadian Family Physician 43 (2007): 1928-34; Leah Steele, Louise LemieuxCharles, Jocalyn Clark, and Richard Glazier, "The Impact of Policy Changes on the Health of Recent Immigrants and Refugees in the Inner City," Canadian Journal of Public Health 93, no. 2 (2002): 118-22; UNAIDS \& WHO, "AIDS Epidemic Update: December 2007."

8. Josephine Pui-Hing Wong, Pushpa Kanagaratnam, Susanda Yee, and Kenneth Fung, Intersecting Sexuality, Gender, Race and Citizenship: Mental Health Issues Faced by Immigrants and Refugees Living with HIV/AIDS (Toronto: Asian AIDS Community Services, August 2004); Steele et al., "Impact of Policy Chances."

9. Jonathan Jacobs, Laura Damson, and David Rogers, "One Approach to Care for Patients Infected with Human Immunodeficiency Virus in an Academic Medical Center," Bulletin of the New York Academy of Medicine 73 (1996): 301-13; Carla Mariano, “The Case for Interdisciplinary Collaboration," Nursing Outlook 37 (1989): 285-88; Laurie Sylla, R. Douglas Bruce, Adeeba Kamarulzaman, and Frederick Altice, "Integration and Co-location of HIV/AIDS, Tuberculosis and Drug Treatment Services," International Journal on Drug Policy 18 (2007): 306-12; Paul Volberding, "Improving the Outcomes of Care of Patients with Human Immunodeficiency Virus Infection," New England Journal of Medicine 334 (1996): 729-31.

10. Ada Sue Hinshaw and Patrick DeLeon, "Toward Achieving Multidisciplinary Professional Collaboration," Professional Psychology: Research and Practice 26, no. 2 (1995): 115-16; Stephen Kline, Conceptual Foundations for Multidisciplinary Thinking, (Stanford, CA: Stanford University Press, 1995); Yossi Korazim-Kõrösy, Terry Mizrahi, Chana Katz, Amnon Karmon, Martha Lucia Garcia, and Martha Bayne Smith, "Towards Interdisciplinary Community Collaboration and Development," Journal of Community Practice 15 (2007): 13-44; Lori Van Manen, Susan Jane Laschinger Tracey Stevenson, and Frances Fothergill-Bourbonnais, "The Nature of Multidisciplinary HIV Care in the Ambulatory Setting: A Synthesis of the Literature," Journal of the Association of Nurses in AIDS Care 16, no. 5 (2005): 49-57.

11. R. Douglas Bruce and Frederick Altice, "Clinical Care of the HIV-Infected Drug User," Infectious Disease Clinics of North America 21 (2007): 149-79; Antoine Douaihy, Roger Jou, Tad Gorske, and Ihsan Salloum, "Triple Diagnosis: Dual Diagnosis and HIV Disease, Part 1," The AIDS Reader 13 (2003): 331-32, 339-41; Joyce Seiko Kobayashi and Walter Standridge, "An Integrated Program for Comprehensive HIV Care," New Directions for Mental Health Services 87 (2000): 111-18.
12. William Housely, Interaction in Multidisciplinary Teams (London: Ashgate, 2003).

13. Wilson Lo, Ted MacGovern, and Judith Bradford, "Association of Ancillary Services with Primary Care Utilization and Retention for Patients with HIV/AIDS," AIDS Care 14 (2002): S45-S57; Manya Magnus, Norine Schmidt, Kathryn Kirkhart, Cathy Schieffelin, Nomi Fuchs, Barbara Brown, and Patricia Kissinger, "Association between Ancillary Services and Clinical and Behavioral Outcomes among HIVInfected Women," AIDS Patient Care and STDs 15 (2001): 137-45, http://www.cinahl.com/cgi-bin/refsvc?jid=501\& accno $=2001092581$.

14. Curtis Handford, Anne-Marie Tynan, Julia Rackal, and Richard Glazier, "Setting and Organization of Care for Persons Living with HIV/AIDS," Cochrane Database of Systematic Reviews 3 (2009): 1469-93; Roz Lasker and Elisa Weiss, "Broadening Participation in Community Problem Solving: A Multidisciplinary Model to Support Collaborative Practice and Research," Journal of Urban Health: Bulletin of the New York Academy of Medicine 80 (2003): 14-47; Antoinette McCallin, "Interdisciplinary Practice-A matter of Teamwork: And Integrated Literature Review," Journal of Clinical Nursing 10 (2001): 419-28; Renslow Sherer, et al., "HIV Multidisciplinary Teams Work: Support Services Improve Access to and Retention in HIV Primary Care," AIDS Care 14, Supplement 1 (2002): S31-S44; Tomas Soto, James Bell, and Michelle Pillen, "Literature on Integrated HIV Care: A Review," AIDS Care 16, Supplement 1 (2004): S43-S55; Van Manen et al., "Nature of Multidisciplinary HIV care."

15. Gillian Gould, Kerri Viney, Michele Greenwood, John Kramer, and Paul Corben, "A Multidisciplinary Primary Healthcare Clinic for Newly Arrived Humanitarian Entrants in Regional NSW: Model of Service Delivery and Summary of Preliminary Findings," Australian and New Zealand Journal of Public Health 34 (2010): 326-29.

16. Canadian HIV/AIDS and Legal Network, "Canada's Immigration Policy"; Klein, HIV/AIDS and Immigration; Alan Li, "Immigrants, Refugees and Non-status People with HIV," chap. 17 in Managing Your Health: A Guide for People Living with HIV (Toronto: Canadian AIDS Treatment Information Exchange, 2009).

17. Bisaillon, "Human rights."

18. Krentz and Gill, "Five-Year Impact."

19. Angela Burnett and Michael Peel, "Asylum Seekers and Refugees in Britain: Health Needs of Asylum Seekers and Refugees," British Medical Journal 322 (2001): 544-47.

20. Li, "Immigrants, refugees."

21. Fauzia Gardezi, Liviana Calzavara, Winston Husbands, and Wangari Tharao, "HIV/AIDS Stigma in Toronto's African and Caribbean Communities," Campus: A Community Resource in HIV/AIDS-Related CBR 1, no. 2 (Winter 2007): 6.

22. Luciana Ruppenthal, "Two Worlds Colliding: Adjustment of HIV Positive Refugees and Their Health Care 
Professionals in a Montreal HIV Hospital" (presented at Canadian Association of AIDS Care Conference, Vancouver, BC, April 2007).

23. Laura Simich, Morton Beiser, Miriam Stewart, and Edward Mwakarimba, "Providing Social Support for Immigrants and Refugees in Canada: Challenges and Directions," Journal of Immigrant Health 7, no. 4 (2005): 259-68.

24. Ruppenthal, "Two Worlds Colliding."

25. Wong et al., "Intersecting sexuality."

26. Steele et al., "Impact of policy chances."

27. Wong et al., "Intersecting sexuality."

28. Ibid.

29. Tiffany Veinot, "The Case for an Integrated Approach to HIV/AIDS Prevention: Support and Treatment Services in Canada," Journal of HIV/AIDS \& Social Services 5, no. 3/4 (2006): 181-91.

30. Kristine Gebbie, "A Holistic Look at the Human Immunodeficiency Virus Pandemic," Holistic Nursing Practice 10, no. 1 (1995): 1-9.

31. Urie Bronfenbrenner, The Ecology of Human Development: Experiments by Nature and Design (Cambridge, MA: Harvard University Press, 1979).

32. Edison Trickett, "Context, Culture, and Collaboration in AIDS Interventions: Ecological Ideas for Enhancing Community Impact," Journal of Primary Prevention 23, no. 2 (2002): 169.

33. Holly Dando and Charles Finlon, "Social work in an Interdisciplinary HIV/AIDS Program," chap. 24 in A History of AIDS Social Work in Hospitals: A Daring Response to an Epidemic, ed. B. Willinger and A. Rice (New York: Hawthorn Press, 2003); Claude Olivier and Margaret Dykeman, "Challenges to HIV Service Provision: The Commonalities for Nurses and Social Workers," AIDS Care 15, no. 5 (2003): 649-63; Anthony J. Pinching, "Models of Clinical Care," AIDS 3, Supplement 1 (1989): S209-S213; Tracy Riley, "HIV-Infected Client Care: Case Management and the HIV Team," Clinical Nurse Specialist 6, no. 3 (1992): 136-41; Soto, Bell, and Pillen, "Literature on Integrated HIV Care," S50; Van Manen et al., "The Nataure of Multidisciplinary HIV care"; Sherer et al., "HIV Multidisciplinary Teams Work."

34. Korazim-Kõrösy et al., "Towards Interdisciplinary Community Collaboration."

35. Gebbie, "A Holistic Look."

36. Hinshaw and DeLeon, "Toward Achieving Multidisciplinary Professional Collaboration”; Judy Lifshitz, "Developing the Role of a Social Worker within a Multidisciplinary Team in an HIV/AIDS Outpatient Clinic," Social Worker 64, no. 4 (1996): 34-42; Pinching, "Models of Clinical Care."

37. Dando and Finlon, "Social Work."

38. Housely, Interaction in Multidisciplinary Teams.

39. Laura Ellingson, "Communication, Collaboration and Teamwork among Health Professional," Communication Research Trends 21, no. 3 (2002): 1-44; Hinshaw and DeLeon, "Toward Achieving Multidisciplinary Professional
Collaboration"; Olivier and Dykeman, "Challenges to HIV Service Provision."

40. Van Manen et al., "Nature of Multidisciplinary HIV care."

41. Soto, Bell, and Pillen, "Literature on Integrated HIV Care," S50.

42. Laura Bronstein, "A Model for Interdisciplinary Collaboration," Social Work 48, no. 3 (2003): 297-306; Lasker and Weiss, "Broadening participation."

43. John Creswell, Quantitative Inquiry and Research Design: Choosing among Five Approaches, 2nd ed. (Thousand Oaks, CA: Sage, 2007).

44. Ibid., 73.

45. Robert Yin, Case Study Research: Design and Methods, 3rd ed., (Thousand Oaks, CA: Sage, 2004).

46. Deborah Padgett, Qualitative Methods in Social Work Research, 2nd ed. (Thousand Oaks, CA: Sage, 2008).

47. Ibid.

48. Yin, Case Study Research.

49. Sheena Sargeant and J. Evin Jones, Barriers in Access to Primary Health Care for Young HIV+ Women: A Qualitative Research Study, 2008, accessed June 20, 2009, http:// pwn.bc.ca/wp-content/uploads/files/Barriers\%20in $\% 20$ Access \% 20 to \% 20 Primary\%20 Health \% 20 Care \% 20 for\%20Young\%20HIV\%20Women-A\%20Qualitative\%20 Research\%20Study.pdf.

50. Creswell, Quantitative Inquiry.

51. Kline, Conceptual Foundations for Multidisciplinary Thinking; Korazim-Kõrösy et al., "Towards Interdisciplinary Community Collaboration"; McCallin, "Interdisciplinary Practice"; Van Manen et al., "Nature of Multidisciplinary HIV care."

52. Ellingson, "Communication"; Hinshaw and DeLeon, "Toward Achieving Multidisciplinary Professional Collaboration"; Olivier and Dykeman, "Challenges to HIV Service Provision."

53. Ellingson, "Communication."

54. Li, Immigrants, Refugees.

55. Canadian HIV/AIDS and Legal Network, "Canada's Immigration Policy”; Militza Zencovich, Kerry Kennedy, Douglas W. MacPherson, and Brian Gushulak, "Immigration Medical Screening and HIV Infection in Canada," International Journal of STD \& AIDS 17 (2006): 813-16.

56. Canadian HIV/AIDS and Legal Network, "Canada’s Immigration Policy."

57. Pottie et al., "Prevalence of selected preventable and treatable diseases"; "Refugees Must Pay for Drugs: Quebec Pharmacists Group," CBC News, January 25, 2011, accessed January 25, 2011, http://www.cbc.ca/news/canada/ montreal/story/2011/01/25/mtl-refugees-pharmacists .html.

58. Sandra Elgersma, "Immigration Status and Legal Entitlement to Insured Health Services," Publication No. PRB 08-28E (Ottawa, ON: Library of Parliament 2008); Baukje Miadema, Ryan Hamilton, and Julie Easley, "Climbing the 
Walls: Structural Barriers for Refugee Newcomers in Canada," Canadian Family Physician 54 (2008): 335-36.

59. Miadema, Hamilton, and Easley, "Climbing the Walls."

60. Eric Lawson, Fauzia Gardezi, Liviana Calzavara, Winston Husbands, Ted Myers, and Wangeri Esther Tharao, "HIV/ AIDS, Stigma, Denial, Fear and Discrimination: Experiences and Responses of People from African and Caribbean Communities in Toronto" (Toronto: African and Caribbean Council on HIV/AIDS in Ontario, 2006).

61. Daniel Cobos and Jonathan Winston Jones, "Promoting Passage through Care: How to Best Serve Undocumented Immigrants with HIV,' Journal of the Association of Nurses in AIDS Care 19, no. 4 (2009): 320-24.

62. Lester Parrott, "Constructive Marginality: Conflicts and Dilemmas in Cultural Competence and Anti-oppressive Practice," Social Work Education 28 (2009): 617-30.

63. Parrott, "Constructive Marginality," 620.

64. Maja Korac, "Cross-Ethnic Networks, Self-Reception System, and Functional Integration of Refugees from the Former Yugoslavia in Rome," Journal of International Migration and Integration 2 (2001): 4.

65. C. D. Handford, A. M. Tynan, J. M. Rackal, and R. H. Glazier, "Setting and Organization of Care for Persons Living with HIV/AIDS," Cochrane Database of Systematic Reviews 3 (2009): 1469-93; M. F. Parry, J. Stewart, P. Wright, and G. McLeod, "Collaborative Management of HIV Infection in the Community: An Effort to Improve the Quality of HIV Care," AIDS Care 16, no. 6 (2004): 690-99.
Heather Mah, MSW, has been involved in the field of HIV for the past seven years across Canada and currently works with refugee populations in social housing in London, UK. She has also been involved with a systematic review at the McGill Centre for Research on Children and Families and with research at Hope and Cope Wellness Centre in Montreal.

Nicole Ives is an assistant professor at McGill University School of Social Work. She has been working with refugee populations in the resettlement context for the past twelve years in Canada, Denmark, and the United States. Her research and teaching areas are focused on refugee resettlement practice and policy, comparative migration policy, and the role of faith-based organizations in resettlement as well as Indigenous social and educational policies and Indigenous social work education. Her research has explored Bosnian refugee resettlement in the United States and Denmark, congregational sponsorship of refugees, and refugee family reunification. Ives has published articles focused on refugee resettlement as it relates to integration and sponsorship and has presented her research on refugee issues both nationally and internationally.

(C) Heather Mah and Nicole Ives, 2010. This open-access work is licensed under a Creative Commons Attribution-NonCommercial 4.0 International License, which permits use, reproduction and distribution in any medium for non-commercial purposes, provided the original author(s) are credited and the original publication in Refuge: Canada's Journal on Refugees is cited. 